higher in amplitude, longer in duration, less sharp, and had a higher spike parameter. (Frost JD et al. Epilepsia May/June 1992 33:531536.)

A report of unilateral opercular macrogyria underlying benign childhood epilepsy with centrotemporal rolandic spikes in an 18 year old boy emphasizes the need for MRI in detecting neuronal migration disorders and other structural lesions in cases of apparent idiopathic partial epilepsies. (Ambrosetto G. Epilepsia May/June 1992 33:499503.)

\title{
CSF ACTH LEVELS IN INFANTILE SPASMS
}

ACTH levels in CSF of 14 infants with massive infantile spasms were significantly lower than those of controls in a study from the University of Southern California and Childrens Hospital of Los Angeles, CA. Differences in cortisol levels between patients and controls were not statistically significant. The authors postulate the involvement of the corticotropinreleasing hormone-ACTH-glucocorticoid regulatory loop in the pathophysiology of infantile spasms. (Baram TZ, et al. Brain-adrenal axis hormones are altered in the CSF of infants with massive infantile spasms. Neurology June 1992; 42:1171-1175.) (Reprints: Dr. Tallie Z. Baram, Division of Neurology (\#82), CHLA, P.O. Box 54700, Los Angeles, CA 90054-0700.)

COMMENT. Further studies of this type should help to determine the respective merits of low dose versus high dose ACTH therapy in infantile spasms (see Progress in Pediatric Neurology, ed Millichap JG. $1991 ; 30-34)$.

\section{ANTICONVULSANT DRUGS}

\section{CHEWABLE VERSUS REGULAR CARBAMAZEPINE}

A comparison of chewable and regular carbamazepine (CBZ tablets) in 44 children receiving chronic CBZ monotherapy is reported from the IWK Children's Hospital, Halifax, Nova Scotia. Weekly levels showed no consistent differences between the 1 month on chewable $\mathrm{CBZ}$ and on regular CBZ. Seizure control and rates of reported side effects were similar in the 2 periods. Chewable CBZ produced higher peak CBZ levels in 5 patients and a similar number had higher peaks with regular CBZ. (Camfield $P$ et al. The pharmacology of chewable versus regular carbamazepine in chronically treated children with epilepsy. Can J Neurol Sci May 1992; 19:204-207.)

COMMENT. Chewable and regular CBZ appear to have similar pharmacokinetics but individual patients may show some differences and those with peak level side effects using one form of $\mathrm{CBZ}$ should receive the alternative form of tablet.

A therapeutic bioequivalency study of brand name versus generic carbamazepine in 40 epileptic patients studied at the Bowman Gray 
School of Medicine, Winston-Salem, NC showed that both performed equally well in clinical efficacy and bioequivalency. (Oles KS et al. Neurology June 1992; 42:1147-1153.)

\section{VALPROATE METABOLITES AND HYPERAMMONEMIA}

The association between valproate metabolism (VPA) and VPA induced hyperammonemia was studied at Hirosaki University Hospital, Japan. In 53 monopharmacy patients, plasma $\mathrm{NH}_{3}$ levels did not depend on age, VPA dosage or serum levels and showed a negative correlation with the 4-en metabolite of VPA. In polypharmacy patients, plasma $\mathrm{NH}_{3}$ levels were significantly higher, while 2-en VPA serum level and bilirubin were lower than in monopharmacy patients. (Kondo $\mathrm{T}$ et al. Is 2-propyl-4-pentonoic acid (4-en), a hepatotoxic metabolite of valproate, responsible for valproateinduced hyperammonemia? Epilepsia May/June 1992; 33:550-554.) (Reprints: Dr. S. Kaneko at Department of Neuropsychiatry, Hirosaki 036, Japan.)

COMMENT. This study indicates that young age and high VPA serum levels are not risk factors for hyperammonemia induced by VPA and 4en metabolite is not causally related to this adverse effect. These authors had previously reported that young age, polypharmacy, and high VPA serum level enhance the susceptibility to VPA hepatotoxicity by altering the metabolism of VPA and by increasing the conversion of VPA to 4-en, the most toxic VPA metabolite (see Ped Neur Briefs March 1992, $\underline{6}: 21)$.

In 43 children with epilepsy who were treated with VPA monotherapy or polytherapy, serum levels of copper were significantly lower than in normal control patients, whereas serum zinc levels were not altered. (Kaji M et al. Epilepsia May/June 1992; $\underline{33: 555-557 .)}$

Valproate and carbamazepine, and in a lesser frequency, phenytoin and phenobarbital, were the most common causes of red blood cell macrocytosis in children in a study from the Children's Medical Center, Dallas, TX (Pappo AS et al. Pediatrics June 1992; 89:1063-1067). Macrocytosis and pancytopenia may be the first manifestation of bone marrow failure and aplastic anemia. An MCV of more than $90 \mathrm{fL}$ in a patient taking antiepileptic medications deserves careful monitoring.

\section{CEREBROVASCULAR DISEASE}

\section{IDIOPATHIC STROKE}

Of 4 children with idiopathic stroke syndrome examined at the Department of Neurosciences and Pediatrics, UMD-New Jersey Medical School and the University of Rochester Medical Center, all 4 were heterozygous for human leukocyte antigen (HLA-B51). Control samples from 3 patients with non-idiopathic stroke syndrome failed to reveal the HAL-B51 marker. (Mintz M, Epstein LG, Koenigsberger MR. Idiopathic childhood 